\title{
Isolation and Detection of Methicillin-Resistant Staphylococci in Healthy Broilers in Nsukka Southeast, Nigeria
}

\author{
Ifeoma C. UGWU ${ }^{1}$, Madubuike U. ANYANWU' ${ }^{1 *}$, Chidozie C. UGWU ${ }^{2}$, Jude N. OKORO ${ }^{1}$ \\ ${ }^{1}$ University of Nigeria, Nsukka, Faculty of Veterinary Medicine, Department of Veterinary Pathology and Microbiology, Enugu State, Nigeria; \\ ifeoma.cugwu@unn.edu.ng; okorojude75@gmail.com; madubuike.anyanwu@unn.edu.ng(*correspondingauthor) \\ ${ }^{2}$ Federal University of Technology, Department of Animal Science and Technology, Owerri, Nigeria; chidozie.ugwu@futo.edu.ng
}

\begin{abstract}
This study was conducted to isolate and detect methicillin-resistant staphylococci (MRS) in healthy broilers in Nsukka Southeast, Nigeria and determine the antibiogram of the isolates. Cloacal and skin swabs were collected from each of 101 randomly sampled broilers meant for slaughter. The samples were processed for isolation and identification of methicillin-resistant Staphylococcus species, following standard methods. Confirmation of methicillin-resistance by the isolates was done using penicillin binding protein 2a (PBP2a) kit. Phenotypic resistance of the isolates to antimicrobial agents was determined using disc diffusion method. Out of 202 samples processed, 200 (99.01\%) yielded positive growth of staphylococci on oxacillin-supplemented oxacillin-resistance staphylococcal agar base (ORSAB). A total of 200 methicillin-resistant staphylococcal isolates were obtained. Of these, 91 (45.5\%) were identified as methicillin-resistant coagulase-positive Staphylococcus (MRCoPS), while 109 (54.5\%) were identified as methicillin-resistant coagulase-negative Staphylococcus species (MRCoNS). Out of the 91 MRCoPS, 53 (58.2\%) were identified as methicillin-resistant Staphylococcus aureus (MRSA). Resistance of the isolates was $99.5 \%$ to erythromycin and chloramphenicol, $100 \%$ to oxacillin, $76.5 \%$ to gentamicin, $96.5 \%$ to clindamycin, $92.5 \%$ to ciprofloxacin, 99\% to sulphamethoxazole/trimethoprim and tetracycline, and 98.5\% to streptomycin and cefoxitin. All the isolates were multidrug resistant. This study has shown that healthy broilers reared and slaughtered in Nsukka Southeast, Nigeria harbour multidrugresistant MRS and thus serve as their reservoirs.
\end{abstract}

Keywords: gallinaceous, staphylococcus, multidrug-resistance

\section{Introduction}

The increased use of antimicrobial agents in both human and veterinary medicine has led to the emergence of antimicrobial resistance in bacterial organisms (Geser et al., 2012). In food-producing industry, for animals, especially poultry, different antimicrobial agents are used extensively in sub-therapeutic/therapeutic doses for growth promotion, routine disease prevention and treatment of bacterial diseases (Gilchrist et al., 2007; Waters et al., 2011). This indiscriminate practice is usually worse in developing countries including Nigeria, where there are no strict regulations on the use of antimicrobials in food-producing animals. This has led to increased resistance to most of the antimicrobials used in food animal production, especially the beta-lactams (penicillins) and cephalosporins (Wulf and Voss, 2008). Staphylococci are opportunistic pathogens, part of normal commensal flora of skin and mucous membranes of food-producing animals (Quinn and Markey, 2003). They are among the most prevalent causes of clinical infections globally and have garnered substantial public attention due to increasing mortality associated with antimicrobial resistance (Waters et al., 2011). Staphylococci resist all beta-lactams by the production of beta-lactamases (Livermore and Brown, 2001; Quinn and Markey, 2003). The use of beta-lactamaseresistant cephalosporins (such as methicillin or oxacillin) as a solution to beta-lactam resistance in staphylococci was shortlived when these organisms also became resistant to the betalactamase-resistant cephalosporins (Wulf and Voss, 2008). Staphylococcal isolates that are resistant to methicillin are those that have acquired mec $A$ gene located on staphylococcal chromosomal cassettes (SCCs), which encodes the expression of penicillin binding protein $2 \mathrm{a}$ (PBP2a), a factor that reduces the binding affinity of penicillins and cephalosporins to the cell wall of organisms (Weese and Van Djuikeren, 2010).

Isolation of methicillin-resistant staphylococci (MRS) from livestock generated a lot of interest in recent years (Wulf and Voss, 2008; Febler et al., 2011). Identification of livestock-associated MRS (LA-MRS) in food-producing animals raised questions regarding the presence of MRS in food of animal origin and its impact on food chain (Klutymans, 2010; Kwon et al., 2006; Febler et al., 2011). Epidemiological studies showed that LA-MRS not only colonized livestock which served as their reservoirs, but also contaminated meat of both colonized animals and that of 
others during slaughter, overcame species barrier and resulted in zoonotic infections in humans with direct (handling and consumption of contaminated meat) and indirect exposure to the livestock and their products (Ekkelenkamp et al., 2006; Fitzgerald, 2012; Schaumburg et al., 2013). LA-MRS are considered major pathogens causing nosocomial and many hospital-linked infections worldwide (Febler et al., 2011). Outcomes of these infections are often fatal because of the complications and difficulty of their treatment, which is associated with multidrug resistance of LA-MRS (Febler $e t$ al., 2011). Therefore, determination of antimicrobial resistance profile of LA-MRS isolates is crucial for empirical treatment of infections associated with LA-MRS.

Recently, there is an increasing numbers of reports on the isolation of LA-MRS from humans, farm and slaughterhouse environments and animals (Mulders et al., 2010; Petinaki and Spiliopoulous, 2012). This necessitated surveillance studies to assess food-producing animals as potential reservoirs of MRS in different parts of the world such as America (Smith et al., 2008; Waters et al., 2011), Europe (Armand-Lefevre et al., 2005; Friese et al., 2012; Huijsdens et al., 2006; Meemken $e t$ al., 2008; Pomba et al., 2009; Voss et al., 2005;), Asia (Lee, 2003; Moon et al., 2007) and South Africa (Ateba et al., 2010). These studies were conducted in food-producing mammals. Surveillance studies to detect the occurrence of LA-MRS in poultry are rather scanty. However, studies conducted in Belgium (Nemati et al., 2008; Nemeghaire et al., 2013; Persoons et al., 2009), The Netherland (Mulders et al., 2010) and Germany (Friese et al., 2013; Schaumburg et al., 2013) implicated poultry as potential reservoir of MRS.

In available literature, there is only a report on surveillance of food-producing animals (ruminants) as reservoirs of MRS in Nigeria (Mai-siayama et al., 2014). No study has been conducted to screen poultry birds reared and slaughtered in Nsukka Southeast, Nigeria, as potential reservoirs of MRS, whereas broilers constitute a major source of protein for the Nsukka populace. These broilers may habour MRS which are consumed together with the broiler meat by the Nsukka population, hence increasing the dissemination of antimicrobial resistance genes. The objective of this study, therefore, was to isolate and detect MRS in broilers slaughtered in Nsukka Southeast, Nigeria and determine the antimicrobial resistance profile of the isolates.

\section{Materials and methods}

\section{Sampling}

Broilers meant for slaughter at Nsukka abattoir between May and August 2014 were sampled. A total of 101 broilers were randomly selected. Cloaca and breast skin swabs were collected from each of the bird using sterile swab sticks moistened with sterile normal saline. The samples were transported aseptically and processed within 1 hour of collection in the Veterinary Microbiology Laboratory, Department of Veterinary Pathology and Microbiology, University of Nigeria, Nsukka.

Isolation of presumptive methicillin-resistant staphylococci from broilers

The swabs from cloaca and breast skin were aseptically inoculated into brain heart infusion broth supplemented with $6.5 \%$ sodium chloride for selective isolation of staphylococci and incubated at $37^{\circ} \mathrm{C}$ for 24 hours aerobically. A loopful of the cultures was sub-cultured onto oxacillinresistance staphylococcal agar base (ORSAB) supplemented with $1.0 \mathrm{mg}$ of oxacillin and 25,000 IU of polymyxin, and incubated at $37^{\circ} \mathrm{C}$ for 24 hours. The morphology of different colonial types were appropriately described and recorded. Purification of the cultures was done using nutrient agar supplemented with $6.5 \%$ sodium chloride and incubated at $37^{\circ} \mathrm{C}$ for 24 hours. Pure cultures of the staphylococcal isolates were then inoculated onto slants of nutrient agar supplemented with $6.5 \%$ sodium chloride, incubated at $37^{\circ} \mathrm{C}$ for 24 hours and stored in refrigerator at $4{ }^{\circ} \mathrm{C}$ as stock cultures until needed for further analysis. Phenotypic characterization of the isolates was done by subjecting them to various tests such as Gram staining, catalase, coagulase, haemolysis and biofilm following standard procedures.

\section{Evaluation of $\mathrm{PBP} 2 \mathrm{a}$ production by presumptive} methicillin-resistant staphylococcal isolates from broilers

The staphylococcal isolates were assessed for the production of PBP2a using the Slidex MRS Detection, which is based on the agglutination of latex particles sensitized with monoclonal antibodies against PBP2a. The test was carried out and interpreted according to the manufacturer's instructions.

Determination of antibiogram of methicillin-resistant staphylococcal isolates from broilers

Antimicrobial susceptibility of the MRS isolates was determined by the disc diffusion method (CLSI, 2012). The isolates were sub-cultured on nutrient agar, incubated at 37 ${ }^{\circ} \mathrm{C}$ for 24 hours. Then colonies of each of the isolate were adjusted to $0.5 \mathrm{McF}$ arland's turbidity standard (equivalent to $1 \times 10^{8}$ colony forming unit $/ \mathrm{ml}$ ) in sterile nutrient broth. The standardized broth cultures were incubated for 10 minutes at $37^{\circ} \mathrm{C}$ and then inoculated onto sterile Mueller-Hinton agar plates using sterile swab stick. Ten antibacterial agents were used and they included: oxacillin $(1 \mu \mathrm{g})$, erythromycin (15 $\mu \mathrm{g})$, choramphenicol $(30 \mu \mathrm{g})$, streptomycin $(10 \mu \mathrm{g})$, tetracycline $(30 \mu \mathrm{g})$, gentamicin $(30 \mu \mathrm{g})$, clindamycin $(2 \mu \mathrm{g})$, ciprofloxacin $(5 \mu \mathrm{g})$, sulphamethoxazole/trimethoprim (25 $\mu \mathrm{g})$ and cefoxitin $(30 \mu \mathrm{g})$. The discs were placed strategically on the inoculated nutrient agar plate. The plates were incubated at $37^{\circ} \mathrm{C}$ for 24 hours. After incubation the zone of inhibition around each disc was measured with a meter rule. Each test was performed in triplicate and the mean inhibitory zone diameter (IZD) calculated to the nearest whole millimeters for each isolate and each antibacterial agent. The IZD was interpreted as susceptible, intermediate or resistant according to the Clinical and Laboratory Standards Institute (CLSI) (2012) criteria for aerobic isolates.

\section{Results}

\section{Isolation rates of $M R S$ from broilers}

Out of 202 samples processed, 200 (99.01\%) yielded positive growth of staphylococci on oxacillin-supplemented ORSAB (Table 1). From these positive samples, a total of 200 presumptive methicillin-resistant staphylococcal (pMRS) isolates were obtained. All the pMRS isolates were positive for PBP2a production test. Out of these 200 methicillin-resistant 
22

staphylococcal isolates, 91 (45.5\%) were identified as coagulase-positive Staphylococcus (MRCoPS), while 109 (54.5\%) were identified as coagulase-negative Staphylococcus species (CoNS) (Table 2). Out of the 91 MRCoPS, 53 (58.2\%) were obtained from cloaca samples, while 38 (41.8\%) were obtained from the breast skin samples. Out of 91 MRCoPS, 53 (58.2\%) were identified as methicillin-resistant Staphylococcus aureus (MRSA) strains. Of these, 33 (62.3\%) isolates were obtained from the cloaca samples, while 20

Table 1. Isolation rate of methicillin-resistant staphylococci from broilers

\begin{tabular}{lcccc}
\hline \multicolumn{1}{c}{ Sample } & $\begin{array}{c}\text { Number } \\
\text { of } \\
\text { broilers } \\
\text { sampled }\end{array}$ & $\begin{array}{c}\text { Number } \\
\text { of } \\
\text { positive } \\
\text { culture }\end{array}$ & $\begin{array}{c}\text { Number } \\
\text { (Percentage) } \\
\text { of isolates } \\
\text { obtained }\end{array}$ & $\begin{array}{c}\text { Number of } \\
\text { isolates } \\
\text { positive for } \\
\text { PBP2a }\end{array}$ \\
\hline Cloaca swab & 101 & 100 & $100(99.01)$ & 100 \\
Breast skin swab & 101 & 100 & $100(99.01)$ & 100 \\
Total & 202 & 200 & 200 & 200 \\
\hline
\end{tabular}

PBP2a $=$ Penicillin binding protein 2a

Table 2. Isolation rates of methicillin-resistant Staphylococcus species from broilers

\begin{tabular}{|c|c|c|c|c|}
\hline \multirow[t]{2}{*}{ Sample } & \multirow{2}{*}{$\begin{array}{l}\text { Number } \\
\text { of isolates } \\
\text { obtained }\end{array}$} & \multicolumn{3}{|c|}{ Number (Percentage) of isolates obtained } \\
\hline & & MRCoPS & MRSA & MRCoNS \\
\hline Cloaca swab & 100 & $53(58.2)$ & 33 & $47(43.1)$ \\
\hline Breast skin swab & 100 & $38(41.8)$ & 20 & $62(56.9)$ \\
\hline Total & 200 & $91(45.5)$ & $53(58.2)$ & $109(54.5)$ \\
\hline
\end{tabular}

(37.7\%) isolates were obtained from the breast skin samples. Of the 109 MRCoNS, 47 (43.1\%) were isolated from cloaca samples, while $62(56.9 \%)$ were isolated from breast skin samples.

Antibiogram of methicillin-resistant staphylococcal isolates from broilers

Out of 200 isolates, $199(99.5 \%)$ isolates were resistant to erythromycin, $200(100 \%)$ to oxacillin, $153(76.5 \%)$ to gentamicin, 199 (99.5\%) to chloramphenicol, $193(96.5 \%)$ to clindamycin, 185 (92.5\%) to ciprofloxacin, 198 (99\%) to sulphamethoxazole/trimethoprim, 198 (99\%) to tetracycline, 197 (98.5\%) to streptomycin and 197 (98.5\%) to cefoxitin (Table 3 and Fig. 1). The methicillin-resistant staphylococcal isolates exhibited 14 multidrug resistance patterns with E-

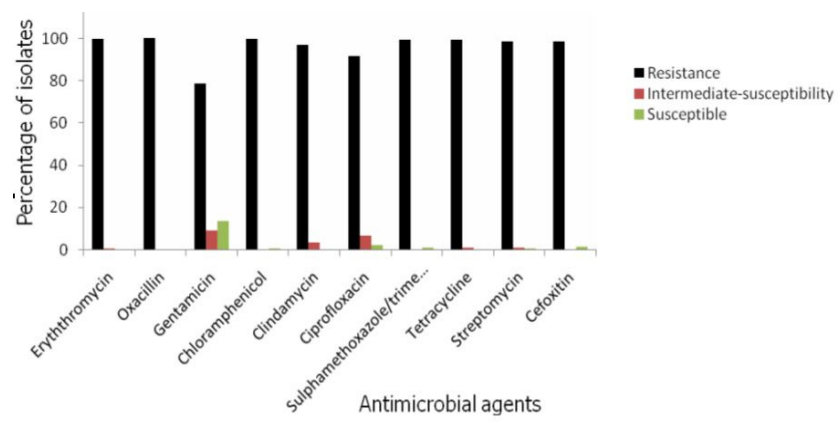

Fig. 1. Antibiogram of methicillin (oxacillin) resistant staphylococcal isolates from broilers
Table 3. Antibiogram of methicillin-resistant staphylococcal isolates from broilers

\begin{tabular}{|ccccc}
\hline \multirow{2}{*}{ Antimicrobial agent } & $\begin{array}{c}\text { Potency } \\
(\mu \mathrm{g})\end{array}$ & \multicolumn{3}{c}{ Number(Percentage) of isolate $(n=200)$} \\
\cline { 3 - 5 } & 15 & $199(99.5)$ & $1(0.5)$ & $0(0)$ \\
\hline Erythromycin & 1 & $200(100)$ & $0(0$ & $0(0)$ \\
\hline Oxacillin & 1 & $153(76.5)$ & $19(9.5)$ & $28(14)$ \\
\hline Gentamicin & 30 & Intermediate & Susceptible \\
\hline Chloramphenicol & 30 & $199(99.5)$ & $0(0)$ & $1(0.5)$ \\
\hline Clindamycin & 2 & $193(96.5)$ & $7(3.5)$ & $0(0)$ \\
\hline Ciprofloxacin & 5 & $185(92.5)$ & $12(6)$ & $3(1.5)$ \\
\hline Sulphamethoxazole/ & 25 & $198(99)$ & $0(0)$ & $2(1)$ \\
trimethoprim & & $198(99)$ & $2(1)$ & $0(0)$ \\
\hline Tetracycline & 30 & 109 & $1(0.5)$ \\
\hline Streptomycin & 10 & $197(98.5)$ & $2(1)$ & $3(1.5)$ \\
\hline Cefoxitin & 30 & $197(98.5)$ & $0(0)$ &
\end{tabular}

Table 4. Frequency of resistance patterns exhibited methicillin-resistant staphylococcal isolates from broilers

\begin{tabular}{|c|c|c|c|}
\hline $\mathrm{S} / \mathrm{N}$ & Resistance pattern & Frequency & Percentage \\
\hline 1 & OX-DA-FOX & 1 & 0.5 \\
\hline 2 & OX-C-CIP-TE-S-FOX & 1 & 0.5 \\
\hline 3 & E-OX-C-DA-CIP-TE-S-FOX & 1 & 0.5 \\
\hline 4 & E-OX-C-DA-SXT-TE-S & 1 & 0.5 \\
\hline 5 & E-OX-C-DA-SXT-S-FOX & 1 & 0.5 \\
\hline 6 & E-OX-C-SXT-TE-S-FOX & 1 & 0.5 \\
\hline 7 & E-OX-C-DA-SXT-TE-S-FOX & 2 & 1 \\
\hline 8 & E-OX-GN-C-CIP-SXT-S-FOX & 1 & 0.5 \\
\hline 9 & E-OX-GN-C-DA-CIP-SXT-TE-S & 1 & 0.5 \\
\hline 10 & E-OX-GN-C-DA-CIP-SXT-TE-FOX & 1 & 0.5 \\
\hline 11 & E-OX-GN-C-DA-SXT-TE-S-FOX & 7 & 0.35 \\
\hline 12 & E-OX-GN-C-CIP-SXT-TE-S-FOX & 3 & 1.5 \\
\hline 13 & E-OX-C-DA-CIP-SXT-TE-S-FOX & 41 & 20.5 \\
\hline \multirow[t]{2}{*}{14} & E-OX-GN-C-DA-CIP-SXT-TE-S-FOX & 138 & 69 \\
\hline & Total & 200 & 100 \\
\hline
\end{tabular}

$\mathrm{E}=$ erythromycin, $\mathrm{OX}=$ oxacillin, $\mathrm{GN}=$ Gentamicin, $\mathrm{C}=$ competențelor, $\mathrm{DA}=$ clindamycin, $\mathrm{CIP}=$ ciprofloxacin, $\mathrm{SXT}=$ sulphamethoxazole/timethoprim, $\mathrm{TE}=$ tetracycline, $S=$ streptomycin, FOX = cefoxitin

Table 5. Number of antimicrobial class to which methicilin-resistant staphylococcal isolates from broilers were resistant

\begin{tabular}{cc}
\hline $\begin{array}{c}\text { Number of antimicrobial } \\
\text { class }\end{array}$ & $\begin{array}{c}\text { Number (Percentage) of isolates } \\
\text { resistant }\end{array}$ \\
\hline 2 & $1(0.5)$ \\
5 & $1(0.5)$ \\
8 & $181(90.5)$ \\
7 & $14(7)$ \\
6 & $3(1.5)$ \\
Total & $200(100)$ \\
\hline
\end{tabular}

OX-GN-C-DA-CIP-SXT-TE-S-FOX being the most prevalent pattern (Table 4$)$. Out of 200 isolates, $1(0.5 \%)$ was resistant to 2 and 5 classes of the antibacterial agents tested, 3 (1.5\%) were resistant to 6 classes, 14 (7\%) to 7 classes and 181 (90.5\%) to 8 classes (Table 5 ).

\section{Discussions}

In this study, MRS were isolated from cloaca and breast skin of broilers slaughtered in Nsukka Southeast, Nigeria and the antibiogram of the isolates was determined. The fact that all the isolates grew on oxacillin-supplemented ORSAB suggest that they are methicillin-resistant strains. Production 
of PBP2a by all the isolates confirmed that they are methicillin-resistant strains and thus may harbour mec $A$ gene which encodes for the expression of PBP2a (Peersons et al., 2009). Isolation of 200 (99.01\%) staphylococcal isolates from 202 samples processed indicates that the medium used (oxacillin-supplemented ORSAB) was highly selective and effective for primary isolation of MRS from the samples. The 99.01\% MRS isolation rate from both cloaca and breast skin of the sampled broilers, suggests that both sites were highly colonized by MRS. The high isolation rate of MRS in this study suggests that the farms in which these birds were raised could be heavily contaminated with MRS. Colonization of farm environments including poultry farms by MRS have been reported (Petersen $e$ t al., 2013). The isolates could have colonized the breast skin of the broilers when they lied down on contaminated litter, since they use their breasts to make direct contact with the floor. It is also possible that the handlers of the birds transferred the organisms to the birds. Reports have shown that MRS can be transferred from humans, especially animal handlers, to animals on direct and/or indirect contact (Petinaki and Spiliopoulous, 2012). However, colonization of the cloacae of the birds may have resulted following ingestion of the MRS from contaminated litter. Staphyloccoci constitute part of the normal flora of the skin and mucous membrane of birds (Quinn and Markey, 2003), hence, it is possible that the isolates acquired methicillin-resistance genes from other bacterial organisms picked from their environment or those contracted from their handlers. The MRS isolation rate recorded in this study is higher than 34.6 and $41 \%$ MRS isolation rate reported by Mai-siayama et al. (2014) and Waters et al. (2011) from ruminants and processed chicken in Northeast Nigeria and America, respectively. Pletinckx et al. (2010) reported 44.4 and $16.7 \%$ MRSA isolation rate from claoca and skin beneath the wings of broilers, respectively. The variation in the isolation rates in these studies may be related to differences in the rate of contamination of the handlers, farm environments and the animals. The finding in this study suggests that broiler farms in the study area are heavily contaminated with MRS. This may imply that acquisition of methicillinresistance genes is going on at a tremendous rate and proportion among staphylococci colonizing broilers reared and slaughtered in Nsukka. This finding portends health risks to the handlers of these broilers and the consumers.

In this study, the 53 (58.2\%) isolates among the MRCoPS identified as MRSA, produced coagualse and haemolysin, which are important virulent factors of Staphylococcus aureus (Quinn and Markey, 2003). Production of coagulase enables the organism to evade the phagocytic cells while invading its host, whereas haemolysin destroys the host's erythrocytes releasing important nutrients such as iron for bacterial growth (Jarraud et al., 2002). However, the non-haemolytic MRCoPS isolates obtained in this study could be other coagualse-positive staphylococcal species such as $S$. pseudintermedius, S. schlieferi, S. delphini, S. intermedius that colonize farm animals (Morgan, 2008; Quinn and Markey, 2003; Wesse and van Djuikeren, 2010). The Isolation of 109 (54.5\%) MRCoNS in this study suggests that high number of commensal CoNS associated with food-producing animals may be harbouring mec $A$ gene. This finding is important because most investigators tend to neglect the role of CoNS as potential reservoirs and source of transfer of resistance genes among bacterial organisms. CoNS are usually saprophytes in farm environments, thus they are associated with foodproducing animals (Morgan, 2008; Quinn and Markey, 2003). The MRCoNS isolation rate in this study is higher than 6.7\% MRCoNS isolation rate reported by Nnachi et al. (2014) from raw meats (beef, pork, goat and donkey) marketed in Southeast, Nigeria.

The $100 \%$ oxacillin-resistance recorded further proves that the staphylococcal isolates are methicillin-resistant strains. The oxacillin-resistance rate is similar to $100 \%$ oxacillin-resistance reported by Gali et al. (2013) among methicillin-resistant staaphylococcal isolates from bovine milk in Northeast, Nigeria. High rates of resistance to cefoxitin (98.5\%) and ciprofloxacin (92.5\%) in this study suggests again that the isolates may be harbouring mec $A$ gene. Resistance to cefoxitin is used for the confirmation of methicillin-resistance in bacterial organisms (Perry et al., 2004). Resistance to ciprofloxacin is used as a surrogate marker for the identification of MRS (Kunori et al., 2002). The ciprofloxacin resistance observed is higher than 35 and $80 \%$ ciprofloxacin resistance, reported by Mulders et al. (2006) and Waters et al. (2011) among MRSA isolates from broilers and poultry, and processed chicken in Belgium and America, respectively. Pearsoons et al. (2009) reported 100\% ciprofloxacin resistance among MRSA isolates from poultry in Belgium, which is higher than the findings in this study.

High rates of resistance to erythromycin (99.5\%), gentamicin (76.5\%), chloramphenicol (99.5\%), clindamycin (96.5\%), streptomycin (98.5\%), sulphamethoxazole/trimethoprim (99\%) and tetracycline (99\%) suggests that the isolates exerted selection and resistance to these drugs. High rate of streptomycin resistance recorded may be as a result of its frequent use in the study area. Streptomycin is often used with penicillins to exert a broad-spectrum action during treatment of infections in poultry. Resistance to streptomycin may have resulted to the high gentamicin resistance since a gene can encode for resistance to many aminoglycosides (Febler et al., 2011). The gentamicin resistance rate noted is higher than 14.8, 38 and $43.5 \%$ reported by Nemati $e$ al. (2008) and Mulders et al. (2006), and Waters et al. (2011) among MRSA isolates from cloacae of farmed broilers and broilers meant for slaughter, and processed chicken in Belgium and America, respectively. Mulders et al. (2006) and Nemati et al. (2008), and Waters et al. (2011) reported 55, 37 and $8.7 \%$ erythromycin resistance rates among MRSA from broilers in Belgium and America, respectively, which is lower than the findings $(99 \%)$ in this study. Chloramphenicol resistance is comparable to $100 \%$ chloramphenicol resistance reported by Pearsoons et al. (2009) among MRSA isolates from poultry in Belgium, but it is higher than the findings of Nemeghaire et al. (2013), who reported $40 \%$ chloramphenicol resistance among MRSA isolates from broilers and layers in Belgium.

The high tetracycline resistance obtained may be due to indiscriminate use of drugs in broiler production in the study area. Tetracycline is a broad-spectrum antibiotic frequently used for growth-promotion and treatment of bacterial infections in poultry, especially for broilers production in Nigeria (Oluwasile et al., 2014). Thus, the isolates may have been exposed to tetracycline resulting in development of resistance against it. The $99 \%$ tetracycline resistance in this 
24

study is comparable to 90 and $96.9 \%$ tetracycline resistance reported by Mulders et al. (2006) and Febler et al. (2011) among MRSA isolates from broilers meant for slaughter and imported fresh poultry meat in Belgium and Germany, respectively. It is higher than $58.8 \%$ reported by Nemati $e t$ al. (2008) among MRSA isolates from broilers in Belgium. The clindamycin resistance rate contrasts that of Mulders et al. (2006) and Waters et al. (2011) who reported 54 and 8.7\% clindamycin resistance among MRSA isolates from poultry meat in Belgium and America, respectively.

In terms of resistance to classes of antibacterial agents, 198 $(99 \%)$ of the isolates were resistant to three or more classes of the antibacterial agents tested, thus indicating multidrug resistance. The resistance patterns exhibited by the isolates proved further that the isolates were resistant to three or more of the drugs tested. LA-MRS has been widely reported to be multidrug resistant (Waters et al., 2011). It is well documented that mec $A$ gene, which encode for methicillin-resistance in staphylococci, also encodes for resistance to other classes of antimicrobial agents including aminoglycosides, lincosamides, sulfonamides and tetrayclines (Febler et al., 2011; Morris, 2006b). Therefore, the multidrug resistance exhibited by the isolates in this study, pose great health threat to the public (Nemati et al., 2008).

\section{Conclusions}

This study has shown that MRS are associated with broilers reared and slaughtered in Nsukka Southeast, Nigeria, thus these broilers are potential reservoirs for MRS. Since the isolates are multidrug-resistant, they portend adverse impact on the food chain. However, molecular characterization of the isolates to elucidate mec $A$ gene and other genes encoding for resistance to the other antibacterial agents is recommended.

\section{References}

Armand-Lefevre L, Ruimy R, Andremont A (2005). Clonal comparison of Staphylococcus aureus isolates from healthy pig farmers, human controls and pigs. Emerg Infect Dis 11:711-714.

Ateba CN, Mbewe M, Moneoang MS, Bezuidenhout CC (2010). Antibiotic-resistant Staphylococcus aureus isolated from milk in the Mafikeng Area, North West province, South Africa. South Afr J Sci 106(11/12):doi: 10.4102/sajs.v 106I 11/12.243.

Clinical and Laboratory Standards Institute (CLSI) (2012). Performance standards for antimicrobial susceptibility testing; twenty-second informational supplement, M100-S22 32(3):62-78.

Ekkelenkamp MB, Sekkat M, Carpaij N, Troelstra A, Bonten MJ (2006). Endocarditis due to MRSA originating from pigs. Ned Tijdschr Geneeskd 150:2442-2447.

Febler AT, Kadlec K, Hassel M, Hauschild T, Eidam C, Ehricht R, Monecke S, Schwarz S (2011). Characterization of methicillinresistant Staphylococcus aureus isolates from food and food products of poultry origin in Germany. Appl Environ Microbiol 77(20):7151-7157.

Fitzgerald JR (2012). Human origin for livestock-associated methicillin-resistant Staphylococcus aureus. mBio 3(2):e00082-12 doi:10.1128/mBio.00082-12.
Friese A, Schulz J, Hoehle L, Fetsch A, Tenhagen BA, Hartung J, Roesler U (2012). Occurrence of MRSA in air and housing environment of pig barns. Vet Microbiol 158:129-135.

Friese A, Schulz J, Zimmermann K, Tenhagen BA, Fetsch A, Hartung J, Rösler U (2013). Occurrence of livestock-associated methicillinresistant Staphylococcus aureus in turkey and broiler barns and contamination of air and soil surfaces in their vicinity. Appl Environ Microbiol 79(8):2759-2766.

Gali AU, Kabir J, Umoh VJ, Mohammed B, Jacob KP Kwaga (2013). Methicillin-resistant Staphylococcus aureus (MRSA) in fresh and fermented milk in Zaria and Kaduna, Nigeria. Int J Drug Res Tech 3(3):67-75.

Geser N, Stepha R, Hachler H (2012). Occurrence and characteristics of extended-spectrum $\beta$-lactamase (ESBL) producing enterobacteriaceae in food producing animals, minced meat and raw milk. BMC Vet Res 8:21.

Gilchrist MJ, Greko C, Wallinga DB, Beran GW, Riley DG, Thorne PS (2007) The potential role of concentrated animal feeding operations in infectious disease epidemics and antibiotic resistance. Environ Health Persp 115:313-316.

Huijsdens XW, van Dijke BJ, Spalburg E, van Santen-Verheuvel MG, Heck ME, Pluister GN, Voss A, Wannet WJ, de Neeling AJ (2006). Community-acquired MRSA and pig farming. Ann Clin Microbiol Antimicrob 5:26-29.

Jarraud S, Mougel C, Thioulouse J, Lina G, Meugnier H, Forey F, Nesme X, Etienne J, Vandenesh F (2002). Relationships between Staphylococcus aureus genetic background, virulence factors, agr groups (alleles), and human disease. Infect Immun 70:631-641.

Kluytmans JA (2010). Methicillin-resistant Staphylococcus aureus in food products: cause for concern or case for complacency? Clin Microbiol Infect 16(1):11-15.

Kunori T, Cookson B, Roberts JA, Stone S, Kibbler C (2002). Costeffectiveness of different MRSA screening methods. J Hosp Infect 51:189-200.

Kwon N, Park KT, Jung WK, Youn HY, Lee Y, Kim SH, Bae W, Lim JY, Kim JY, Kim JM, Hong SK, Park YH (2006). Characteristics of methicillin-resistant Staphylococcus aureus isolated from chicken meat and hospitalized dogs in Korea and their epidemiological relatedness. Vet Microbiol 117:304-312.

Lee JH (2003). Methicillin(oxacillin)-resistant Staphylococcus aureus strains isolated from major food animals and their potential transmission to humans. Appl Env Microbiol 69:6489-6494.

Livermore DM, Brown DF (2001). Detection of beta-lactamase mediated resistance. J Antimicrob Chemother 48:59-64.

Mai-siyama IB, Okon KO, Adamu NB, Askira UM, Isayaka TM, Adamu SG, Mohammed A (2014). Methicilli-resistant Staphylococcus aureus (MRSA) colonization rate in among ruminants animals slaughtered for human consumption and contact persons in Maiduguri, Nigeria. Afr J Microbiol Res 8(27):2643-2649.

Meemken D, Cuny C, Witte W, Eichler U, Staudt R, Blaha T (2008). Occurrence of MRSA in pigs and in humans involved in pig production - preliminary results of a study in the northwest of Germany. Dtsch. Tier arztl Wochenschr 115:132-139. 
Moon JS, Lee AR, Kang HM, Lee ES, Kim MN, Paik YH, Park YH, Joo YS, Koo HC (2007). Phenotypic and genetic antibiogram of methicillin-resistant staphylococci isolated from bovine mastitis in Korea. J Dairy Sci 90:1176-1185.

Morgan M (2008). Methicillin-resistant Staphylococcus aureus and animals: zoonosis or humanosis? J Antimicrob Chemother 62(6):1181-1187.

Morris D, Rook K, Shofer F, Rankin S (2006b). Screening of Staphylococcus aureus, Staphylococcus intermedius, and Staphylococcus schleiferi isolates obtained from small companion animals for antimicrobial resistance: A retrospective review of 749 isolates (2003-04). Vet Dermatol 17:332-337.

Mulders MN, Haenen APJ, Geenen PL, Vesseur PC, Poldervaart ES, Bosch T, Hiujsdens XW, Hengeveld PD, Dam-Deisz WDC, Graat EAM, Mevius D, Voss A, Van De Giessen AW (2010). Prevalence of livestock-associated MRSA in broiler flocks and risk factors for slaughterhouse personnel in The Netherlands. Epidemiol Infect 138:743755.

Nemati M, Hermans K, Lipinska U, Denis O, Deplano A, Struelens M, Devriese LA, Pasmans F, Haesebrouck F (2008). Antimicrobial resistance of old and recent Staphylococcus aureus isolates from poultry: first detection of livestock-associated methicillin-resistant strain ST398. Antimicrob Agents Chemother 52:3817-3819.

Nemeghaire S, Roelandt S, Argudín MA, Haesebrouck F, Butaye P (2013). Characterization of methicillin-resistant Staphylococcus aureus from healthy carrier chickens, Avian Pathol 42(4):342-346.

Nnachi AU, Emele FE, Ukaegbu CO, Agah MV, Udu-Ibiam OE, Chukwu OS, Agwu MM (2014). Methicillin-resistant Staphylococcus aureus (MRSA) in raw meat and meat handlers in Onitsha, Nigeria. Eur J Prev Med 2(1):9-15.

Oluwasile BB, Agbaje M, Ojo OE, Dipeolu MA (2014). Antibiotic usage pattern in selected poultry farms in Ogun state. Sokoto J Vet Sci 12(1):45-50.

Perry JD, Davies A, Butterworth LA, Hopley LJ, Nicholson A, Gould KF (2004). Development and evaluation of chromogenic medium for methicillin-resistant Staphylococcus aureus. J Clin Microbiol 42(10):4519-4523.

Persoons D, Van Hoorebeke S, Hermans K, Butaye P, de Kruif A, Haesebrouck F, Dewulf J (2009). Methicillin-resistant Staphylococcus aureus in poultry. Emerg Infect Dis 15:452-453.

Petersen A, Stegger M, Heltberg O, Christensen J, Zeuthen A, Knudsen LK, Urth T, Sorum M, Schouls L, Larsen J, Skov R, Larsen AR (2013). Epidemiology of methicillinresistant Staphylococcus aureus carrying the novel $\operatorname{mec} C$ gene in Denmark corroborates a zoonotic reservoir with transmission to humans. Clin Microbiol Infect 19:16-22.
Petinaki E, Spiliopoulous I (2012). Methicillin-resistant Staphylococcus aureus among companion and food-chain animals: impact of human contacts. Clin Microbiol Infect 18:626-634.

Pletinckx LJ, Verhegghe M, Dewulf J, Crombé F, De Bleecker Y, Rasschaert G, Goddeeris BM, De Man I (2010). Screening of poultry-pig farms for methicillin-resistant Staphylococcus aureus: sampling methodology and within herd prevalence in broiler flocks and pigs. Infect Genet Evolut 11(8):2133-2137.

Pomba C, Hasman H, Cavaco LM, daFonseca JD, Aarestrup FM (2009). First description of methicillin-resistant Staphylococcus aureus (MRSA) CC30 and CC398 from swine in Portugal. Int J Antimicrob Agents 34:193-194.

Quinn PJ, Markey BK (2003). Concise Review of Veterinary Microbiology, $2^{\text {nd }}$ edition. Blackwell Publishing Limited, Oxford. p. 5-9.

Schamburg F, Köck R, Mellmann A, Köksal M, Jurke A, Becker K, Freidrich W (2013). Livestock-associated methicillin-resistant Staphylococcus aureus (MRSA) as causes of human infection and colonization in Germany. PLoS ONE 8(2):e55040 doi:10.1371/journal.pone.0055040.

Smith TC, Male MJ, Harper AL, Moritz-Koroloev E, Kroeger JS, Diekema DJ, Herwaldt L (2008). Isolation of methicillin-resistant Staphylococcus aureus (MRSA) from swine in the Midwestern United States. International Conference on Emerging Infectious Diseases, Atlanta, USA Abstract.

Voss A, Loeffen F, Bakker J, Klaassen C, Wulf M (2005). Methicillin-resistant Staphylococcus aureus in pig farming. Emerg Infect Dis 11:1965-1966.

Waters AE, Contente-Cuomo T, Buchhagen J, Liu CM, Watson L, Pearce K, Foster JT, Bowers J, Driebe EM, Engelthaler DM, Keim PS, Price LB (2011). Multidrugresistant Staphylococcus aureus in US meat and poultry. Clin Infec Dis 52:1-4 doi:10.1093/cid/cir181.

Weese JS, Van Duijkeren E (2010). Methicillin-resistant Staphylococcus aureus and Staphylococcus pseudintermedius in veterinary medicine. Vet Microbiol 140:418-429.

Wulf M, Voss A (2008). MRSA in livestock animals - an epidemic waiting to happen? Clin Microbiol Infect 14:519-521. 